Canadian

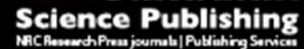

Canadian Journal of Chemistry Revue canadienne de chimie

\title{
Oxygen-17 NMR Spectroscopy of Water Molecules in Solid Hydrates
}

\begin{tabular}{|r|l|}
\hline Journal: & Canadian Journal of Chemistry \\
\hline Manuscript ID & cjc-2015-0547.R1 \\
\hline Manuscript Type: & Article \\
\hline Complete List of Authors: & $\begin{array}{l}\text { Nour, Sherif; University of Ottawa } \\
\text { Widdifield, Cory; University of Ottawa } \\
\text { Kobera, Libor; University of Ottawa } \\
\text { Burgess, Kevin; University of Ottawa, } \\
\text { Errulat, Dylan; University of Ottawa } \\
\text { Terskikh, Victor; University of Ottawa, Chemistry } \\
\text { Bryce, David; University of Ottawa, }\end{array}$ \\
\hline Keyword: & nmr, oxygen-17, quadrupolar coupling, hydrogen bonding, water \\
\hline
\end{tabular}

\section{SCHOLARONE}

Manuscripts 


\section{Oxygen-17 NMR Spectroscopy of Water Molecules in Solid Hydrates}

Sherif Nour, Cory M. Widdifield ${ }^{\mathfrak{f}}$, Libor Kobera, Kevin M. N. Burgess ${ }^{\S}$, Dylan Errulat, Victor V. Terskikh, and David L. Bryce*

Department of Chemistry and Biomolecular Sciences

University of Ottawa

Ottawa, Ontario

K1N6N5

Canada

phone 613-562-5800 ext 2018

fax 613-562-5170

emaildbryce@uottawa.ca

*author to whom correspondence may be addressed

${ }^{£}$ Present address: Department of Chemistry, Durham University, Science Site, Durham DH1 3LE, United Kingdom

${ }^{\S}$ Present address: London Research and Development Centre, Agriculture and Agri-Food Canada, London, Ontario, Canada N5V 4T3 
Abstract. Oxygen-17 solid-state NMR studies of waters of hydration in crystalline solids are presented. The ${ }^{17} \mathrm{O}$ quadrupolar coupling and chemical shift $(\mathrm{CS})$ tensors, and their relative orientations, are measured experimentally at room temperature for $\alpha$-oxalic acid dihydrate, barium chlorate monohydrate, lithium sulfate monohydrate, potassium oxalate monohydrate, and sodium perchlorate monohydrate. The ${ }^{17} \mathrm{O}$ quadrupolar coupling constants $\left(C_{\mathrm{Q}}\right)$ range from 6.6 to $7.35 \mathrm{MHz}$ and the isotropic chemical shifts range from -17 to $19.7 \mathrm{ppm}$. The oxygen CS tensor spans vary from 25 to $78 \mathrm{ppm}$. These represent the first complete CS and electric field gradient tensor measurements for water coordinated to metals in the solid state. Gauge-including projector-augmented wave density functional theory calculations overestimate the values of $C_{\mathrm{Q}}$, likely due to librational dynamics of the water molecules. Computed CS tensors only qualitatively match the experimental data. The lack of strong correlations between the experimental and computed data, and between these data and any single structural feature is attributed to motion of the water molecules and to the relatively small overall range in the NMR parameters relative to their measurement precision. Nevertheless, the isotropic chemical shift, quadrupolar coupling constant, and CS tensor span clearly differentiate between the samples studied, and establish a 'fingerprint' ${ }^{17} \mathrm{O}$ spectral region for water coordinated to metals in solids.

Keywords. Nuclear magnetic resonance, water, quadrupolar coupling, hydrogen bonding, chemical shifts, density functional theory, ${ }^{17} \mathrm{O}$, solid-state NMR 


\section{Graphical abstract}

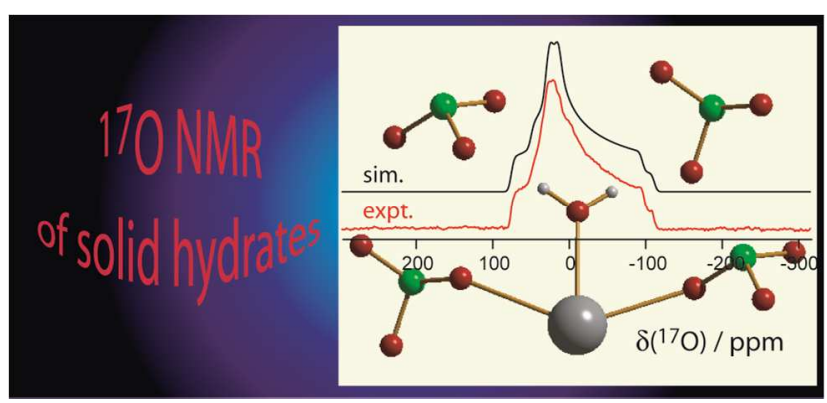




\section{Introduction}

Water is essential to life, innumerable biochemical and inorganic processes, chemical reactions, and the structure and properties of various materials. ${ }^{1,2}$ Water molecules play key structural roles in organic, biological, and inorganic hydrates., ${ }^{3,4,5,6,7,8}$ The number of water molecules which crystallize in the unit cell generally has a significant impact on the overall structure and symmetry of the crystal. This can be of particular importance in mineralogy, ${ }^{9}$ in the pharmaceutical industry, ${ }^{10,11}$ and in the study of pseudopolymorphism in general. ${ }^{12,13}$ Water molecules very often participate in hydrogen bonds in solids, thus contributing to the arrangement of molecules during crystallization and in the final solid obtained. Nuclear magnetic resonance (NMR) spectroscopy has played a pivotal role in the characterization of hydrogen bonds, generally through the interpretation of spectral data for the ${ }^{1} \mathrm{H}$ nucleus. For example, ${ }^{1} \mathrm{H}$ chemical shifts are known to be excellent indicators of the presence and strength or geometry of hydrogen bonds in solution and in the solid state. ${ }^{14,15} \mathrm{Wu}$ et al. ${ }^{16}$ have characterized the ${ }^{1} \mathrm{H}$ chemical shift (CS) tensor for water molecules in a series of solid hydrates and shown the relationship between the CS tensor principal components $\left(\delta_{11}, \delta_{22}, \delta_{33}\right)$ and the geometry of the hydrogen bond. Combinations of these components may also be used to describe the isotropic chemical shift $\left(\delta_{\text {iso }}=\left(\delta_{11}+\delta_{22}+\delta_{33}\right) / 3\right)$, span $\left(\Omega=\delta_{11}-\delta_{33}\right)$, and skew $\left(\kappa=3\left(\delta_{22}-\delta_{\text {iso }}\right) / \Omega\right)$ parameters.

Studying the oxygen environment in solid hydrates via NMR spectroscopy is challenging for several reasons. The only NMR-active oxygen nuclide, ${ }^{17} \mathrm{O}(\operatorname{spin} I=5 / 2)$, has a low natural abundance $(0.037 \%)$ and significant nuclear electric quadrupole moment $(Q)$, generally resulting in low sensitivity and broad line shapes. ${ }^{17}$ The second-order quadrupolar broadening, resulting from the coupling of the quadrupole moment with the electric field gradient (EFG), varies 
inversely with the applied magnetic field strength, suggesting that the use of very high applied magnetic fields will facilitate ${ }^{17} \mathrm{O}$ NMR studies in terms of sensitivity and resolution. The quadrupolar coupling constant $\left(C_{\mathrm{Q}}\right)$ and asymmetry parameter $(\eta)$ may be expressed in terms of the principal components of the EFG tensor $\left(V_{33} \geq V_{22} \geq V_{11}\right)$ :

$$
\begin{aligned}
& C_{\mathrm{Q}}=e Q V_{33} / h \\
& \eta=\left(V_{11}-V_{22}\right) / V_{33}
\end{aligned}
$$

Isotopic enrichment is also commonly used in ${ }^{17} \mathrm{O}$ NMR studies in order to render them practical. Because the ${ }^{17} \mathrm{O}$ solid-state NMR spectra of stationary powdered samples will depend on the ${ }^{17} \mathrm{O}$ $\mathrm{CS}$ tensor in addition to the ${ }^{17} \mathrm{O}$ quadrupolar interaction, it is advantageous to analyze spectra acquired in more than one applied magnetic field when possible, and preferably at least one of these should be strong enough to allow for the precise measurement of the effect of anisotropy of the ${ }^{17} \mathrm{O}$ CS tensor.

Early ${ }^{17} \mathrm{O}$ NMR studies of pure water in various phases have provided some insight into structure and the role of hydrogen bonding. Spiess ${ }^{18}$ et al. reanalyzed ${ }^{17} \mathrm{O}$ NMR data in $\mathrm{D}_{2}{ }^{17} \mathrm{O}$ ice reported by Waldstein and Rabideau ${ }^{19}$ and determined that $C_{\mathrm{Q}}=6.66 \pm 0.10 \mathrm{MHz}$ and $\eta=$ $0.935 \pm 0.01$ at about $258 \mathrm{~K}$. These data were compared with those available for liquid and gaseous water to provide some insights into the behaviour and structure of water. Edmonds and Zussman confirmed these data with a pure quadrupole resonance study on $\mathrm{H}_{2}{ }^{17} \mathrm{O}$, finding that $C_{\mathrm{Q}}$ $=6.525 \mathrm{MHz}$ and $\eta=0.925 \pm 0.020$ at $77 \mathrm{~K}^{20}$ Relaxation experiments on liquid water show a range of $C_{\mathrm{Q}}$ values from about 7.9 to $8.3 \mathrm{MHz} .{ }^{21}$ For an isolated molecule of $\mathrm{HD}^{17} \mathrm{O}$ in the gas phase, high-resolution rotational spectroscopy reveals that $C_{\mathrm{Q}}$ is much higher, $10.1450 \pm 0.0053$ MHz, with $\eta=0.559,{ }^{22}$ which may be attributed to a lack of hydrogen bonding. 
Interestingly, to our knowledge the oxygen chemical shift tensor magnitude and orientation in pure water have not been reported. ${ }^{17}$ A typical approach to determining both the ${ }^{17} \mathrm{O}$ quadrupolar coupling parameters and CS tensor parameters would involve the analysis of stationary and magic-angle spinning (MAS) samples of solid ice. Ba et al. have reported the ${ }^{17} \mathrm{O}$ quadrupolar coupling constant for solid ice at various temperatures. ${ }^{23}$ Experimentally, some of the complicating factors in completely determining the ${ }^{17} \mathrm{O}$ quadrupolar and $\mathrm{CS}$ tensor magnitudes, as well as their relative orientation, for pure water, include the following. First, low temperatures are needed to study water in the solid state, and if one wishes to obtain data relevant to static water molecules in the solid state, freezing out of all motion of the water molecules in the solid state requires particularly low temperatures which are not generally amenable to MAS NMR studies. For example, Ba et al. concluded that the quadrupolar parameters they measured at $150 \mathrm{~K}$ are representative of essentially static water molecules. ${ }^{23}$ Second, the CS tensor span is expected to be small relative to the dominant quadrupolar broadening of the spectrum, resulting in difficulties in teasing out all of the relevant information with high precision. Very recently, Michaelis et al. reported a comprehensive ${ }^{17} \mathrm{O}$ solid-state

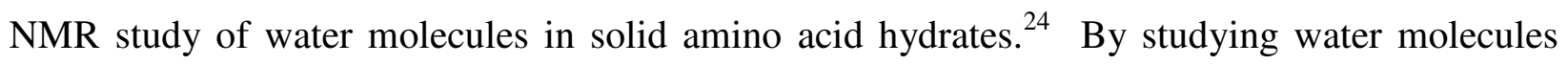
bound in a crystalline lattice, low temperatures are not required to produce a solid sample, thereby greatly facilitating the acquisition and analysis of the data. While there have been several NMR reports in the literature of ${ }^{17} \mathrm{O}$ isotropic chemical shifts measured for water molecules coordinated to metals in solution, ${ }^{25,26,27,28,29,30}$ reports in the solid state are sparse. ${ }^{31,32}$

Herein, we present a ${ }^{17} \mathrm{O}$ solid-state nuclear magnetic resonance (SSNMR) study of $\alpha$ oxalic acid dihydrate (1), barium chlorate monohydrate (2), lithium sulfate monohydrate (3), potassium oxalate monohydrate (4), and sodium perchlorate monohydrate (5), with a focus on 
measuring and understanding the ${ }^{17} \mathrm{O}$ quadrupolar and $\mathrm{CS}$ tensors for the water molecules in these solids. ${ }^{17} \mathrm{O}$ isotopic enrichment and a high-field $\left(B_{0}=21.1 \mathrm{~T}\right)$ magnet are used to increase the sensitivity of the experiments, and a combination of MAS and stationary methods in two applied magnetic field strengths are used to characterize $C_{\mathrm{Q}}$ as well as the small CS tensor spans for ${ }^{17} \mathrm{O}$ of water molecules in the various solids. The samples chosen all have well-defined highprecision single-crystal neutron diffraction structures, thus affording the opportunity to explore the relationship between the measured NMR parameters and the local hydrogen bonding environments. These experimental studies are complemented by gauge-including projector augmented-wave (GIPAW) DFT calculations wherein periodic boundary conditions are employed to model the complete crystal lattices.

\section{Experimental and Computational Methods}

\section{(i) Sample preparation and $X$-ray diffraction}

Natural isotopic abundance samples of compounds 1, 3, 4, and $\mathbf{5}$ were obtained from Sigma Aldrich. ${ }^{17}$ O-enriched water $(40 \%)$ was purchased from Sigma Aldrich and from Cortecnet. ${ }^{17} \mathrm{O}$-enriched samples of compounds $\mathbf{1}, \mathbf{3}, \mathbf{4}$, and $\mathbf{5}$ were prepared using enriched water diluted to 10 to $20 \%$ in ${ }^{17} \mathrm{O}$. Typically, $0.25 \mathrm{~g}$ of the natural abundance samples were dissolved in $0.6 \mathrm{~mL}$ of 10 to $20 \%{ }^{17}$ O-enriched water. After all solids dissolved, the samples were left for four hours at room temperature to allow residual water to evaporate; subsequently, the ${ }^{17} \mathrm{O}$-enriched solid from each sample was collected and carefully ground using a mortar and pestle for powder X-ray and solid-state NMR experiments. An ${ }^{17} \mathrm{O}$-enriched sample of 2 was kindly provided by Prof. Gang Wu (Queen's University). Powder X-ray diffractograms for ${ }^{17} \mathrm{O}-$ 
enriched forms of $\mathbf{1 , 3}, \mathbf{4}$, and $\mathbf{5}$ were obtained using a RIGAKU Ultima IV diffractometer with $\mathrm{Cu} \mathrm{K} \alpha$ radiation $(\lambda=1.54184 \AA)$, and a Bragg-Brentano geometry. The data were collected at a $2 \theta$ scan rate of $1.0 \% \mathrm{~min}$. In all cases the experimental data were in agreement with diffractograms simulated on the basis of the known single-crystal structures (see SI), thereby confirming the phase purity of the samples.

(ii) Solid-state NMR

Oxygen-17 solid-state NMR spectra were acquired in a magnetic field of $9.4 \mathrm{~T}\left(v\left({ }^{17} \mathrm{O}\right)=\right.$ $54.25 \mathrm{MHz})$ at the University of Ottawa and in a magnetic field of $21.1 \mathrm{~T}\left(v\left({ }^{17} \mathrm{O}\right)=121.94 \mathrm{MHz}\right)$ at the National Ultrahigh-field NMR Facility for Solids in Ottawa using Bruker Avance III and Avance II spectrometers, respectively. At $9.4 \mathrm{~T}$, a $4 \mathrm{~mm}$ Bruker HX MAS probe was used to obtain spectra for all powdered samples while at $21.1 \mathrm{~T}$, home built $5 \mathrm{~mm}$ static and $4 \mathrm{~mm}$ Bruker HX MAS probes were used to obtain spectra of the static and $10 \mathrm{kHz}$ MAS samples, respectively. $50 \mathrm{kHz}$ MAS spectra of 1 were obtained using a $1.3 \mathrm{~mm}$ HX Bruker MAS probe. Spectra were referenced to the ${ }^{17} \mathrm{O}$ resonance of tap water at $0 \mathrm{ppm}$. Proton decoupling was used for stationary samples (e.g., $100 \mathrm{kHz}$ continuous wave at 21.1 T). Bloch decay, 90-90 echo, or 90-180 echo sequences were used. A modified quadrupolar-echo $(\pi / 2-\tau-\pi / 2-\tau-$ acquire $)$ pulse sequence, ${ }^{33}$ where the second pulse is replaced by a 90 degree $(\pi / 2)$ pulse was found to produce more accurate ${ }^{17} \mathrm{O}$ NMR line shapes for stationary samples. Excitation pulse lengths were typically $2 \mu \mathrm{s}$ and recycle delays ranged from 3 to $60 \mathrm{~s}$. Further details for each sample are given in the Supporting Information. Data were processed by left-shifting the echo maxima where needed prior to Fourier transformation.

The spectral line shapes were generally fitted to models incorporating anisotropic chemical shift and quadrupolar coupling tensors using WSolids simulation software. ${ }^{34}$ The simulation of 
MAS NMR spectra including spinning sidebands was carried out using Bruker's TopSpin version 3.0. ${ }^{35}$ First, the quadrupolar coupling constant, asymmetry parameter, and isotropic chemical shift were determined by fitting the MAS NMR spectra. The remaining parameters describing the CS tensor and the relative orientation of the CS and EFG tensors were then determined by fitting the spectra of stationary samples.

\section{(iii) Computational details}

Several sets of calculations of the ${ }^{17} \mathrm{O}$ EFG and magnetic shielding tensors were performed (see SI). GIPAW-DFT calculations were performed with CASTEP ${ }^{36}$ version 8.0 , using the default ultrasoft pseudopotentials included within the software package to describe the core electrons. Valence electrons are described using a plane wave basis with an energy cut-off of $700 \mathrm{eV}$. The $k$-point mesh used to sample the Brillouin zone was set as $0.05 \AA^{-1}$. The generalized gradient approximation (GGA) exchange-correlation functional of Perdew, Burke, and Ernzerhof $(\mathrm{PBE})^{37}$ was used throughout. Structures were taken from references 38, 39, 40, 41, 42, and 43. Hydrogen atom positions were optimized in some cases, but the impact on the calculated ${ }^{17} \mathrm{O}$ NMR parameters was relatively minor. Calculations were carried out using the primitive unit cells. See the Supporting Information for further details.

\section{Results and Discussion}

The local structures around the waters of hydration in compounds $\mathbf{1}$ to $\mathbf{5}$ are shown in Figure 1. Some geometrical information, including the water $\mathrm{H}-\mathrm{O}_{\mathrm{w}}-\mathrm{H}$ angle, the $\mathrm{O}_{\mathrm{w}}-\mathrm{H}$ distances, short $\mathrm{O}_{\mathrm{w}} \mathrm{H}^{\cdots} \mathrm{O}$ distances, and short $\mathrm{O}^{\cdots} \mathrm{X}$ distances $(\mathrm{X}=$ alkali/alkaline earth metal cation for 2 to 
5 and $\mathrm{O}$ for $\mathbf{1}$ ) are provided in Table 1. Here, $\mathrm{O}_{\mathrm{w}}$ denotes the oxygen atom of the water molecule. Complete information on the crystal structures are provided in the original references. ${ }^{38,39,40,41,42,43}$ The water molecule in $\alpha$-oxalic acid dihydrate is hydrogen-bonded to three discrete oxalic acid moieties. In compounds $\mathbf{2}$ to $\mathbf{5}$, short distances indicative of water coordinating to the metal cations are noted. None of the compounds are isomorphic and all feature different local hydrogen bonding environments around the waters of hydration.

The ${ }^{17} \mathrm{O}$ solid-state NMR spectra of compounds $\mathbf{1}$ to $\mathbf{5}$, obtained under stationary and MAS conditions, are presented in the figures discussed below along with spectral simulations. For all compounds, the water of hydration has been isotopically enriched. In addition, for compound $\mathbf{1}$, the oxygen atoms of the oxalic acid moiety have also undergone exchange with the enriched ${ }^{17} \mathrm{O}$ water during the sample preparation process. As such, the spectra of $\mathbf{1}$ feature three resonances while the spectra of $\mathbf{2}, \mathbf{3}, \mathbf{4}$, and $\mathbf{5}$ feature single signals from the waters of hydration. The discussion here is focussed on the NMR parameters of the waters of hydration in all compounds. The CS and quadrupolar tensor parameters derived from the spectral fits are presented in Table 2 .

The ${ }^{17} \mathrm{O}$ SSNMR spectra of powdered $\alpha$-oxalic acid dihydrate (1) are shown in Figure 2. Spectra of stationary samples were acquired in magnetic fields of 9.4 and $21.1 \mathrm{~T}$, and a $50 \mathrm{kHz}$ MAS spectrum was also acquired at $21.1 \mathrm{~T}$. Three ${ }^{17} \mathrm{O}$ sites are clearly resolved in the MAS NMR spectrum. The water of hydration is characterized by an isotropic chemical shift of $9.2 \pm$ $1.0 \mathrm{ppm}$, a quadrupolar coupling constant of $7.02 \pm 0.10 \mathrm{MHz}$, and a quadrupolar asymmetry parameter of $0.76 \pm 0.02$. The value of $C_{\mathrm{Q}}$ is within experimental error of the value reported from a single-crystal NMR study, $6.88 \pm 0.20 \mathrm{MHz},{ }^{44}$ while the asymmetry parameter does not agree $(0.93 \pm 0.10)$. This may be at least in part attributed to the neglect of ${ }^{17} \mathrm{O}$ chemical shift 
anisotropy in the earlier study. Fitting of the spectra of stationary samples at two fields further yielded a CS tensor span of $28 \pm 3$ ppm, a CS tensor skew of $-0.7 \pm 0.2$, and non-coincident EFG and CS tensor frames. Spectral parameters for the $\mathrm{C}=\mathrm{O}$ oxygen site and the $\mathrm{C}-\mathrm{OH}$ oxygen site were also obtained as a result of the fitting process, and the relevant EFG and CS tensor parameters are summarized in Table 3. The EFG tensor data are within experimental error of those reported by Wittebort and co-workers in a single-crystal NMR study. ${ }^{45}$ Some of the CS tensor principal components are slightly outside the error ranges quoted in the previous study; we note that while single-crystal NMR studies are typically highly accurate, our study has been carried out in a much higher applied magnetic field (21.1 $\mathrm{T}$ vs $11.7 \mathrm{~T})$, which amplifies the spectral effects of the CS tensor.

Oxygen-17 NMR spectra of powdered barium chlorate monohydrate (2) are shown in Figure 3. Again, spectra of stationary samples were acquired at 9.4 and $21.1 \mathrm{~T}$, and a spectrum of a $10 \mathrm{kHz}$ MAS sample was acquired at 21.1 T. The ${ }^{17} \mathrm{O}$ MAS NMR spectrum was fit taking into account the satellite transitions as well as the central transition, including spinning sidebands. The water of hydration is characterized by the following parameters: $\delta_{\text {iso }}=19.7 \pm 1.0$ ppm, $C_{\mathrm{Q}}=6.91 \pm 0.10 \mathrm{MHz}$, and $\eta=0.97 \pm 0.02$. These values are in fairly good agreement with a previous report. ${ }^{31}$ The value of $C_{\mathrm{Q}}$ reported at $77 \mathrm{~K}$ in 1976 by Shporer and Achlama, ${ }^{46}-7.61 \pm 0.01 \mathrm{MHz}$, is significantly different. The reason for this is not clear, but may be attributable to the temperature difference (the difference in sign may be attributed to the fact that $\eta$ is close to unity). This sample shows the highest water chemical shift in the present study; as barium is quite heavy, this could be in part due to an indirect relativistic effect on the oxygen. Fitting of the spectra of stationary samples provided in addition a CS tensor span of $25 \pm 5$ ppm, 
skew of $-0.7 \pm 0.3$, and the Euler angles describing the non-coincidence of the EFG and CS tensor principal axis systems (Table 2).

The ${ }^{17} \mathrm{O}$ SSNMR spectra of lithium sulfate monohydrate (3) are shown in Figure 4. Again, spectra of stationary samples were acquired at 9.4 and $21.1 \mathrm{~T}$, and a spectrum of a MAS sample was acquired at $21.1 \mathrm{~T}$. The water of hydration is characterized by the following parameters: $\delta_{\text {iso }}=-7 \pm 1 \mathrm{ppm}, C_{\mathrm{Q}}=6.6 \pm 0.1 \mathrm{MHz}$, and $\eta=0.86 \pm 0.02$. This sample has the smallest quadrupolar coupling constant among the data reported presently and additionally amongst those reported by Michaelis et al. for amino acid monohydrates. ${ }^{24}$ Our fitting of multiple datasets for $\mathbf{3}$ provides slightly different parameters for $C_{\mathrm{Q}}$ and $\delta_{\text {iso }}$ compared to a previous report. $^{32}$ Fitting of the spectra of stationary samples provide a span of $30 \pm 10 \mathrm{ppm}$, a skew of $0.6 \pm 0.4$, and Euler angles $\alpha$ and $\beta$ indistinguishable from $90^{\circ}$.

Oxygen-17 NMR spectra of powdered potassium oxalate monohydrate (4) are presented in Figure 5. Again, spectra of stationary samples were acquired at 9.4 and $21.1 \mathrm{~T}$, and a spectrum of a MAS sample was acquired at $21.1 \mathrm{~T}$. A spike at $0 \mathrm{ppm}$ is observed in the MAS NMR spectrum due to residual liquid water in this sample. Contributions from the satellite transitions as well as the central transition were taken into account when fitting the MAS NMR spectrum. The water of hydration is characterized by the following parameters: $\delta_{\text {iso }}=1.1 \pm 1.0$ ppm, $C_{\mathrm{Q}}=6.62 \pm 0.10 \mathrm{MHz}$, and $\eta=0.95 \pm 0.02$. Fitting of the spectra of stationary samples resulted in a relatively large CS tensor span of $78 \pm 10 \mathrm{ppm}$ and a skew of $0.88 \pm 0.12$. Exhaustive attempts to include some low-intensity spectral features observed only at $21.1 \mathrm{~T}$ just under $0 \mathrm{ppm}$ (Figure 5(B)) in the fitting process, while simultaneously attempting to fit the data acquired at 9.4 T, were unsuccessful. The origins of these bumps were thoroughly explored 
through variable-time echo experiments and these were determined to not originate from the main sample (see Supporting Information, Figure S2). The value of the span for $\mathbf{4}$ approaches that reported by $\mathrm{Wu}$ and co-workers for the hydronium ion in $p$-toluenesulfonic acid monohydrate, 87 ppm. $^{47}$

The ${ }^{17} \mathrm{O}$ SSNMR spectra of sodium perchlorate monohydrate (5) are shown in Figure 6. Spectra of stationary and MAS samples were acquired at $21.1 \mathrm{~T}$. A clear contribution from the satellite transitions is seen in the MAS NMR spectrum. The water of hydration is characterized by the following parameters: $\delta_{\text {iso }}=-17 \pm 1.0 \mathrm{ppm}, C_{\mathrm{Q}}=7.35 \pm 0.10 \mathrm{MHz}$, and $\eta=0.72 \pm 0.02$. This is a particularly negative chemical shift relative to the other data reported here and by Michaelis et $a .^{24}$; however, shifts as low as $-141 \mathrm{ppm}$ have been reported in solution for rhodium-water complexes. ${ }^{25}$ This sample also has the largest quadrupolar coupling constant observed in the present study. Fitting the spectrum of a stationary sample provides a CS tensor span of $33 \pm 10 \mathrm{ppm}$, a positive skew, and Euler angles $\alpha$ and $\beta$ indistinguishable from $90^{\circ}$.

Although the range in the observed NMR parameters (e.g., $\delta_{\text {iso }}, C_{\mathrm{Q}}, \Omega$ ) across the entire series of hydrates is expectedly relatively small when compared to the entire possible range known for all oxygen functional groups (i.e., the isotropic CS range is about 1600 ppm for organic compounds and biomolecules, ${ }^{17}$ and values of nearly $20 \mathrm{MHz}$ have been reported for $C_{\mathrm{Q}}{ }^{17,48}$ ), these parameters nevertheless clearly differentiate among all samples and also show subtle but clear differences compared to the dataset reported recently for amino acid hydrates. ${ }^{24}$ The isotropic chemical shifts for the waters of hydration of the compounds studied presently cover a range of nearly $40 \mathrm{ppm}$, from $-17 \pm 1 \mathrm{ppm}$ in sodium perchlorate monohydrate to $19.7 \pm$ $1.0 \mathrm{ppm}$ in barium chlorate monohydrate. Some slightly larger values were found of amino acid hydrates, e.g,. $26 \pm 1 \mathrm{ppm}$ for arginine monohydrate and $31 \pm 1 \mathrm{ppm}$ for cysteine monohydrate. ${ }^{24}$ 
Therefore, on the basis of the data available, $\delta_{\text {iso }}\left({ }^{17} \mathrm{O}\right)$ tends to be smaller for inorganic hydrates than for organic hydrates. The chemical shift of $-17 \mathrm{ppm}$ measured for sodium perchlorate monohydrate falls distinctly outside the previously established range of -4 to $31 \mathrm{ppm}$, bringing the total known range (including the data of Michaelis for organic hydrates) to nearly $50 \mathrm{ppm}$.

The ${ }^{17} \mathrm{O}$ quadrupolar coupling constants range from $6.6 \pm 0.1 \mathrm{MHz}$ in lithium sulfate monohydrate to $7.35 \pm 0.10 \mathrm{MHz}$ in sodium perchlorate monohydrate. In contrast, the value of $C_{\mathrm{Q}}\left({ }^{17} \mathrm{O}\right)$ for water molecules in amino acid hydrates is essentially constant from one compound to the next, i.e., $6.9 \pm 0.1 \mathrm{MHz}$ for asparagine monohydrate and glycylglycine $\mathrm{HCl}$ monohydrate to $7.1 \pm 0.1 \mathrm{MHz}$ for histidine $\mathrm{HCl}$ monohydrate and glycylglutamine monohydrate. Note that we are not able to measure the sign of the quadrupolar coupling constant, but quantum chemical calculations indicate that the sign is positive. This is consistent with positive signs reported by Spiess for solid ice ${ }^{18}$ and by Puzzarini for gaseous water. ${ }^{22}$ The quadrupolar asymmetry parameters cover about $25 \%$ of the possible total range, from $0.72 \pm 0.02$ to $0.97 \pm 0.02$. Similarly large $\eta$ values were obtained for all amino acid hydrates.

Overall, the ${ }^{17} \mathrm{O}$ chemical shift tensor spans are tightly clustered for compounds $\mathbf{1}, \mathbf{2}, \mathbf{3}$, and 4 (25 to $33 \mathrm{ppm}$ with errors of up to $10 \mathrm{ppm}$ ) while that for $\mathbf{5}$ is significantly larger, $78 \pm 10$ ppm. The values obtained for amino acid monohydrates ${ }^{24}$ fall in the middle of these two ranges, i.e., 40 to $50 \mathrm{ppm}$ with an error of $10 \mathrm{ppm}$. The skews of the chemical shift tensor are also shown in Table 2, and are not particularly precise given the small values of the span. The relative orientation of the CS and EFG tensors, as described by Euler angles $(\alpha, \beta, \gamma)$, indicate that the largest component of each of the tensors is exactly or nearly oriented perpendicular to each other ( $\beta$ ranges from 73 to $90^{\circ}$ ). Extensive efforts to establish simple correlations between 
local structural features and the measured NMR parameters were not successful, perhaps due to the relatively small range in the values as well as the relatively large errors on some parameters such as the spans. For example, possible correlations of $C_{\mathrm{Q}}, \delta_{\text {iso }}$, and $\Omega$ with the $\mathrm{O}_{\mathrm{w}} \mathrm{H}^{\cdots} \mathrm{H}$ distance, the $\mathrm{O}_{\mathrm{w}}-\mathrm{H}$ distance, and the $\mathrm{HO}_{\mathrm{w}} \mathrm{H}$ angle were all explored (see Supporting Information). The uniquely large span in $\mathbf{4}$ could possibly be associated with the shortest $\mathrm{O}^{\cdots} \mathrm{H}$ distance within this set of samples, but no general correlation between the CS tensor and this distance could be established across all samples.

The results of GIPAW DFT calculations of the ${ }^{17} \mathrm{O}$ EFG and magnetic shielding tensors for compounds $\mathbf{1}$ through $\mathbf{5}$ are presented in Table 4. These calculations are based on the highest-quality available experimental crystal structures. ${ }^{38,39,40,41,42,43}$ Further computational results on slightly different models are provided in the Supporting Information. The computed quadrupolar coupling constants are of the same order of magnitude as observed experimentally, approximately $8 \mathrm{MHz}$ whereas the experimental data are closer to $7 \mathrm{MHz}$. Interestingly, as noted by $\mathrm{Ba}$ et al., ${ }^{23} \mathrm{C}_{\mathrm{Q}}\left({ }^{17} \mathrm{O}\right)$ values which have been reported for a range of temperatures for pure ice only vary by a few percent, which is not enough to explain the larger deviations between experiment and computation in the present work. Variable-temperature ${ }^{17} \mathrm{O}$ MAS NMR spectra we acquired for barium chlorate hydrate also show only a minor change of about $4 \%$ in $C_{\mathrm{Q}}\left({ }^{17} \mathrm{O}\right)$ over a sixty degree temperature range (from $40^{\circ} \mathrm{C}$ to $-20^{\circ} \mathrm{C}$ ). The calculated spans are also overall in accord with the experimental results; the computed values range from 31 to $65 \mathrm{ppm}$ whereas the experimental data range from about 25 to $78 \mathrm{ppm}$. These computed results, which model the full crystal lattice using periodic boundary conditions, represent an improvement over cluster-based calculations on a related $\mathrm{H}_{3} \mathrm{O}^{+}$system reported by $\mathrm{Wu}$ et al., where a systematic underestimation of the CSA by about 20 ppm was noted. ${ }^{47}$ Somewhat surprisingly, however, no 
clear correlations are noted between the presently reported experimental and computational results (Tables 2 and 4; see also Supporting Information). This finding is largely consistent with the observations of Michaelis et al., ${ }^{24}$ but is generally atypical of current reports in the literature for other systems, including for other "difficult" quadrupolar nuclei and including ${ }^{17} \mathrm{O}$ in other functional groups. Michaelis et al. found somewhat improved agreement with experiment when using X-ray diffraction structures rather than neutron diffraction structures as the models for their calculations, and when using hybrid DFT functionals with cluster models. Overall, our current findings are consistent with those of Michaelis in that further work to understand the discrepancies between the experimental and computed data is required.

Despite the lack of robust correlations between our experimental dataset and specific geometric or bonding features of the water molecule, it is interesting to note the two extremes of the chemical shifts observed for the hydrates of metal complexes ( 2 and $\mathbf{5})$. The most negative shift, -17 ppm, observed for sodium compound $\mathbf{5}$ may possibly be influenced by the smallest $\mathrm{HOH}$ angle $\left(105.65^{\circ}\right)$, the shortest $\mathrm{OH}$ distance $(0.905 \AA)$ and/or the longest $\mathrm{OH}^{\cdots} \mathrm{O}$ distance $(2.153 \AA)$. Similarly, the barium compound 2 features the largest chemical shift (19.7 ppm) and the largest $\mathrm{HOH}$ angle $\left(110.52^{\circ}\right)$. As mentioned, extensive efforts to explore more systematic trends relating particular structural features to the NMR parameters unfortunately did not yield clear and generally applicable correlations. This is likely due to the large number of geometrical and bonding variables and the relatively small range in the NMR parameters measured.

\section{Conclusions}


Oxygen-17 quadrupolar and chemical shift tensors, including magnitudes and relative orientations, have been measured experimentally with solid-state NMR spectroscopy and computed using a gauge-including projector-augmented wave DFT approach for a series of inorganic hydrates and oxalic acid dihydrate. This first such data for water molecules coordinated to metals in solids establishes a clear quadrupolar and chemical shift spectral 'fingerprint' region for such samples. Taken together with the work of Michaelis et al., the present work expands upon the information available on the oxygen chemical shift tensor and its orientation relative to the EFG tensor in waters of hydration. All of the measured parameters vary from sample to sample, demonstrating the sensitivity of ${ }^{17} \mathrm{O}$ NMR to the local environment. For example, the isotropic chemical shift varies from $-17 \mathrm{ppm}$ in sodium perchlorate monohydrate to $+20 \mathrm{ppm}$ in barium chlorate monohydrate. $\delta_{\text {iso }}\left({ }^{17} \mathrm{O}\right)$ tends to be smaller for inorganic hydrates than for organic hydrates. The present work also significantly expands the available information on oxygen chemical shift tensor magnitudes in water molecules, with values of up to $78 \mathrm{ppm}$ determined for the span. Overall, broadly applicable one-to-one correlations between the observed NMR parameters and the local geometry of the water molecule and its hydrogen bonds remain elusive.

\section{Acknowledgements}

We thank Professor Gang Wu for providing the ${ }^{17} \mathrm{O}$-labelled sample of barium chlorate monohydrate used in this work. We thank Mr. Samuel El Mestiri for his contributions to this work. D. L. B. thanks the Natural Sciences and Engineering Research Council (NSERC) of Canada for funding. Access to the 21.1 T NMR spectrometer was provided by the National 
Ultrahigh-Field NMR Facility for Solids (Ottawa, Canada), a national research facility funded by a consortium of Canadian Universities, supported by the National Research Council Canada and Bruker BioSpin, and managed by the University of Ottawa (http://nmr900.ca).

Supporting Information Available. Additional experimental and computational details, spectra, diffractograms, computational results, scatter plots. 
Table 1. Hydrates studied in the present work.

\begin{tabular}{|c|c|c|c|c|c|c|c|c|}
\hline $\begin{array}{l}\text { compound } \\
\text { number }\end{array}$ & compound & formula & $\begin{array}{l}\text { space } \\
\text { group }\end{array}$ & $\begin{array}{c}\mathrm{HO}_{\mathrm{w}} \mathrm{H} \\
\text { angle / 。 }\end{array}$ & $\begin{array}{c}\mathrm{O}_{\mathrm{w}} \mathrm{H} \\
\text { distances } \\
/ \AA\end{array}$ & $\begin{array}{c}\mathrm{O}_{\mathrm{w}} \mathrm{H}^{\cdots} \mathrm{O} \\
\text { distances / }\end{array}$ & $\begin{array}{c}\text { short } \\
\mathrm{O}_{\mathrm{w}} \cdots \mathrm{X} \\
\text { distances }^{\mathrm{a}} \\
/ \AA\end{array}$ & $\begin{array}{c}\text { references to } \\
\text { neutron } \\
\text { diffraction } \\
\text { structures }\end{array}$ \\
\hline 1 & $\begin{array}{c}\alpha \text {-oxalic acid } \\
\text { dihydrate }\end{array}$ & $\mathrm{C}_{2} \mathrm{O}_{4} \mathrm{H}_{2} \cdot 2 \mathrm{H}_{2} \mathrm{O}$ & $P 2_{1} / n$ & 105.70 & $\begin{array}{l}0.954 \\
0.955\end{array}$ & $\begin{array}{c}1.939,2.007 \\
2.439\end{array}$ & $\begin{array}{l}2.411 \\
2.439\end{array}$ & ref. 38,39 \\
\hline 2 & $\begin{array}{c}\text { barium } \\
\text { chlorate } \\
\text { monohydrate }\end{array}$ & $\mathrm{Ba}\left(\mathrm{ClO}_{3}\right)_{2} \cdot \mathrm{H}_{2} \mathrm{O}$ & $I 2 / c$ & 110.52 & 0.925 & 1.988 & $\begin{array}{l}2.786 \\
2.907 \\
2.986\end{array}$ & ref. 40 \\
\hline 3 & $\begin{array}{l}\text { lithium sulfate } \\
\text { monohydrate }\end{array}$ & $\mathrm{Li}_{2} \mathrm{SO}_{4} \cdot \mathrm{H}_{2} \mathrm{O}$ & $P 2_{1}$ & 108.62 & $\begin{array}{l}0.907 \\
0.932\end{array}$ & $2.034,2.164$ & $\begin{array}{l}1.913, \\
1.938, \\
1.951, \\
1.961, \\
1.978, \\
1.994\end{array}$ & ref. 41 \\
\hline 4 & $\begin{array}{c}\text { potassium } \\
\text { oxalate } \\
\text { monohydrate }\end{array}$ & $\mathrm{K}_{2} \mathrm{C}_{2} \mathrm{O}_{4} \cdot \mathrm{H}_{2} \mathrm{O}$ & $C 2 / c$ & 107.62 & 0.963 & 1.801 & $\begin{array}{l}2.755, \\
2.783, \\
2.831, \\
2.869, \\
2.924, \\
2.978\end{array}$ & ref. 42 \\
\hline 5 & $\begin{array}{c}\text { sodium } \\
\text { perchlorate } \\
\text { monohydrate }\end{array}$ & $\mathrm{NaClO}_{4} \cdot \mathrm{H}_{2} \mathrm{O}$ & $C 2 / c$ & 105.65 & $\begin{array}{l}0.905 \\
0.935\end{array}$ & $\begin{array}{c}2.153,2.378 \\
2.390\end{array}$ & $\begin{array}{l}2.360 \\
2.369 \\
2.383 \\
2.430\end{array}$ & ref. 43 \\
\hline
\end{tabular}

a. $\mathrm{X}=$ alkali/alkaline metal cation for $\mathbf{2}$ to $\mathbf{5}$, and $\mathrm{X}=\mathrm{O}$ for $\mathbf{1}$. Upper limit for distances listed here is $2.5 \AA$ for $\mathbf{1}, \mathbf{3}$, and $\mathbf{5}$, and $3.0 \AA$ for 2 and 4 . 
Table 2. Oxygen-17 NMR parameters for water in solid hydrates

\begin{tabular}{|c|c|c|c|c|c|c|c|c|}
\hline & $\delta_{\text {iso }} / \mathrm{ppm}$ & $\left|C_{\mathrm{Q}}\right| / \mathrm{MHz}$ & $\eta$ & $\Omega / \mathrm{ppm}$ & $\kappa$ & $\alpha$ & $\beta$ & $\gamma^{\mathrm{a}}$ \\
\hline $\begin{array}{c}\alpha \text {-Oxalic acid } \\
\text { dihydrate }(\mathbf{1})\end{array}$ & $9.2 \pm 1.0$ & $7.02 \pm 0.10$ & $0.76 \pm 0.02$ & $28 \pm 3$ & $-0.7 \pm 0.2$ & $35 \pm 10$ & $73 \pm 5$ & $0 \pm 20$ \\
\hline $\begin{array}{l}\text { Barium chlorate } \\
\text { monohydrate (2) }\end{array}$ & $19.7 \pm 1.0$ & $6.91 \pm 0.10$ & $0.97 \pm 0.02$ & $25 \pm 5$ & $-0.7 \pm 0.3$ & $70 \pm 10$ & $73 \pm 5$ & $10 \pm 10$ \\
\hline $\begin{array}{l}\text { Lithium sulfate } \\
\text { monohydrate }(\mathbf{3})\end{array}$ & $-7 \pm 1$ & $6.6 \pm 0.1$ & $0.86 \pm 0.02$ & $30 \pm 10$ & $0.6 \pm 0.4$ & $90 \pm 30$ & $90 \pm 10$ & - \\
\hline $\begin{array}{l}\text { Potassium oxalate } \\
\text { monohydrate (4) }\end{array}$ & $1.1 \pm 1.0$ & $6.62 \pm 0.10$ & $0.95 \pm 0.02$ & $78 \pm 10$ & $0.88 \pm 0.12$ & $120 \pm 30$ & $86 \pm 5$ & $120 \pm 30$ \\
\hline $\begin{array}{l}\text { Sodium perchlorate } \\
\text { monohydrate }(\mathbf{5})\end{array}$ & $-17 \pm 1$ & $7.35 \pm 0.10$ & $0.72 \pm 0.02$ & $33 \pm 10$ & $>0.7$ & $90 \pm 30$ & $90 \pm 10$ & - \\
\hline
\end{tabular}

a. The angle $\gamma$ was not observed to have a strong effect on the line shapes for the lithium and sodium compounds.

Table 3. Additional oxygen-17 NMR parameters for $\alpha$-oxalic acid dihydrate

\begin{tabular}{ccccccccc}
\hline & $\delta_{\text {iso }} / \mathrm{ppm}$ & $C_{\mathrm{Q}} / \mathrm{MHz}$ & $\eta$ & $\Omega / \mathrm{ppm}$ & $\kappa$ & $\alpha$ & $\beta$ & $\gamma$ \\
\hline $\mathrm{OH}$ & $184 \pm 2$ & $6.77 \pm 0.10$ & $0.17 \pm 0.02$ & $263 \pm 10$ & $-0.4 \pm 0.1$ & $4 \pm 10$ & $87 \pm 5$ & $83 \pm 20$ \\
$\mathrm{C}=\mathrm{O}$ & $309 \pm 2$ & $8.32 \pm 0.10$ & $0.06 \pm 0.02$ & $480 \pm 10$ & $0.65 \pm 0.10$ & $5 \pm 5$ & $91 \pm 5$ & $30 \pm 10$ \\
\hline
\end{tabular}


Table 4. GIPAW DFT computed ${ }^{17} \mathrm{O}$ magnetic shielding and EFG tensor parameters

\begin{tabular}{ccccccccccccccc}
\hline & Site & $V_{11} /$ a.u. & $V_{22} /$ a.u. & $V_{33} /$ a.u. & $\begin{array}{c}C_{\mathrm{Q}} / \\
\mathrm{MHz}\end{array}$ & $\eta$ & $\begin{array}{c}\sigma_{11} / \\
\mathrm{ppm}\end{array}$ & $\begin{array}{c}\sigma_{22} / \\
\mathrm{ppm}\end{array}$ & $\begin{array}{c}\sigma_{33} / \\
\mathrm{ppm}\end{array}$ & $\begin{array}{c}\sigma_{\text {iso }} / \\
\mathrm{ppm}\end{array}$ & $\begin{array}{c}\Omega / \\
\mathrm{ppm}\end{array}$ \\
\hline & & & & & & & & & & & & & & \\
$\mathbf{1}$ & $\mathrm{H}_{2} \mathrm{O}$ & 0.1813 & 1.1986 & -1.3799 & 8.29 & 0.737 & 249.1 & 283.9 & 294.5 & 275.8 & 45.4 & -0.535 \\
$\mathbf{1}$ & $\mathrm{OH}$ & -0.4776 & -0.6850 & 1.1626 & -6.99 & 0.178 & -93.9 & 100.4 & 213.4 & 73.3 & 307.3 & -0.265 \\
$\mathbf{1}$ & $\mathrm{C}=\mathrm{O}$ & 0.6898 & 0.7036 & -1.3934 & 8.37 & 0.010 & -233.0 & -164.2 & 277.5 & -39.9 & 510.5 & 0.730 \\
$\mathbf{2}$ & $\mathrm{H}_{2} \mathrm{O}$ & 0.1002 & 1.3507 & -1.4509 & 8.72 & 0.862 & 257.2 & 283.1 & 288.5 & 276.3 & 31.3 & -0.654 \\
$\mathbf{3}$ & $\mathrm{H}_{2} \mathrm{O}$ & 0.0799 & 1.2764 & -1.3563 & 8.15 & 0.882 & 280.9 & 302.9 & 338.2 & 307.3 & 57.2 & 0.233 \\
$\mathbf{4}$ & $\mathrm{H}_{2} \mathrm{O}$ & 0.0437 & 1.2078 & -1.2515 & 7.52 & 0.930 & 256.7 & 272.0 & 321.3 & 283.3 & 64.6 & 0.529 \\
$\mathbf{5}$ & $\mathrm{H}_{2} \mathrm{O}$ & 0.0762 & 1.3096 & -1.3858 & 8.33 & 0.890 & 298.1 & 309.8 & 350.6 & 319.5 & 52.5 & 0.552 \\
\hline
\end{tabular}




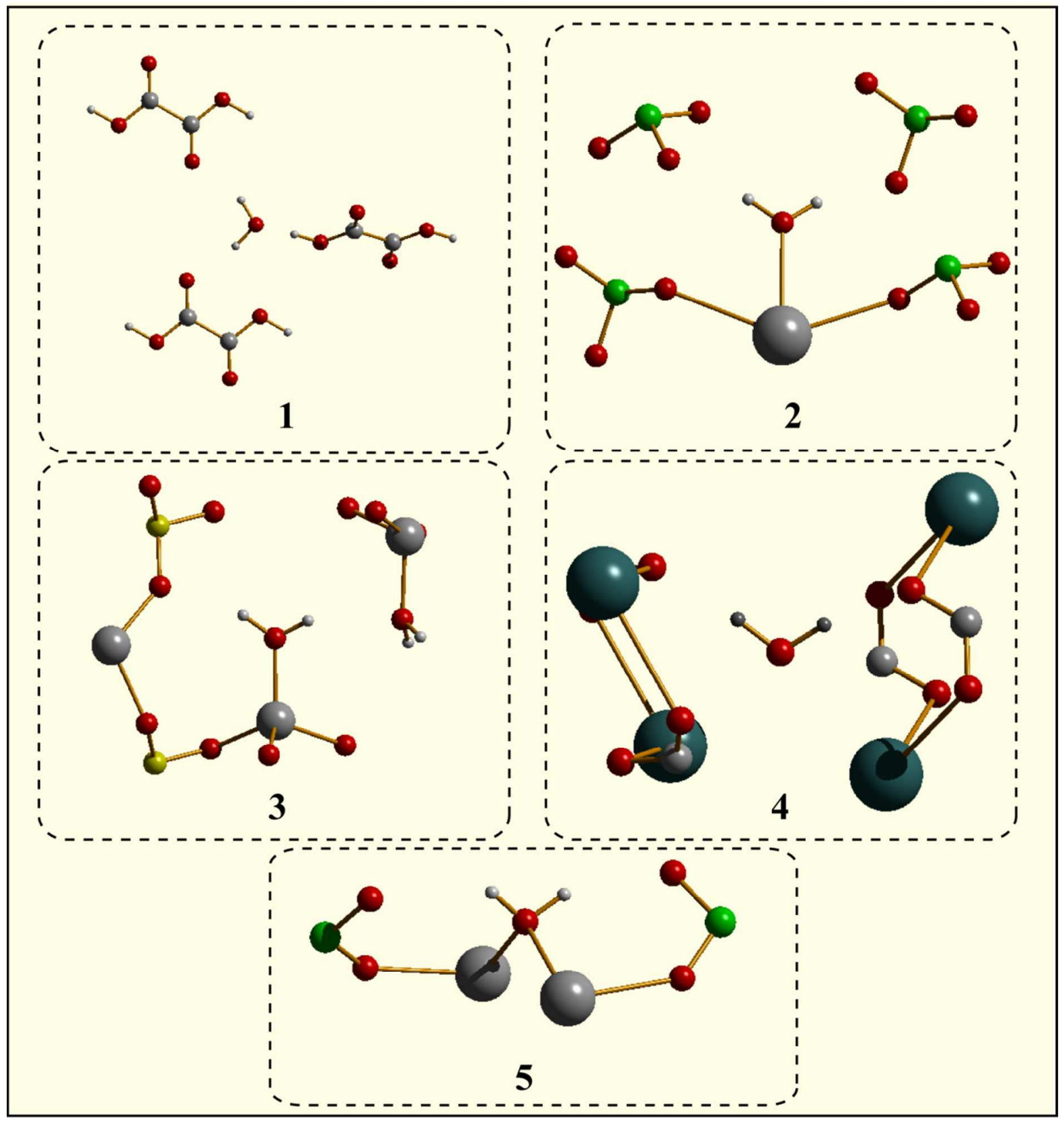

Figure 1. Truncated local structures around the waters of hydration in the studied compounds, taken from the available neutron diffraction structures ( $\alpha$-oxalic acid dihydrate (1), barium chlorate monohydrate (2), lithium sulfate monohydrate (3), potassium oxalate monohydrate (4), and sodium perchlorate monohydrate (5)). Oxygen atoms are in red; hydrogen in light grey; chlorine in green; sulfur in yellow; potassium in dark green; carbon, barium, lithium, and sodium in grey. Bond lines drawn to metal cations indicate close contacts according to standard criteria in the Diamond software. ${ }^{49}$ Note that for all compounds there is a single crystallographically unique water molecule. 

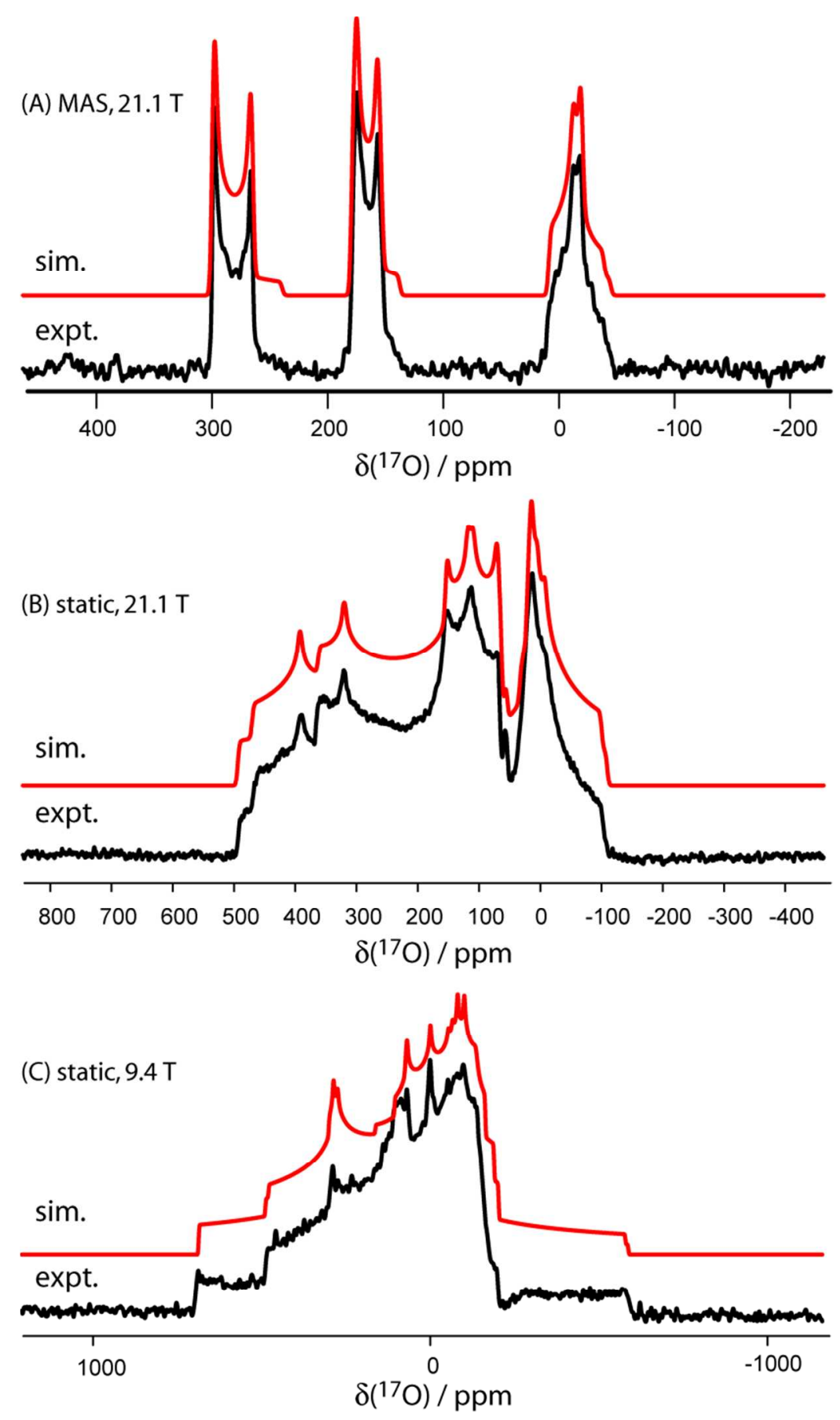

Figure 2. Oxygen-17 NMR spectra of solid powdered $\alpha$-oxalic acid dihydrate (1). The three signals are due the three ${ }^{17} \mathrm{O}$-isotopically enriched oxygen sites in the compound. From left to right: the carbonyl oxygen, the hydroxyl oxygen, and the water oxygen. (A) $50 \mathrm{kHz} \mathrm{MAS}$ at $21.1 \mathrm{~T}$; (B) stationary sample at $21.1 \mathrm{~T}$; (C) stationary sample at $9.4 \mathrm{~T}$. 


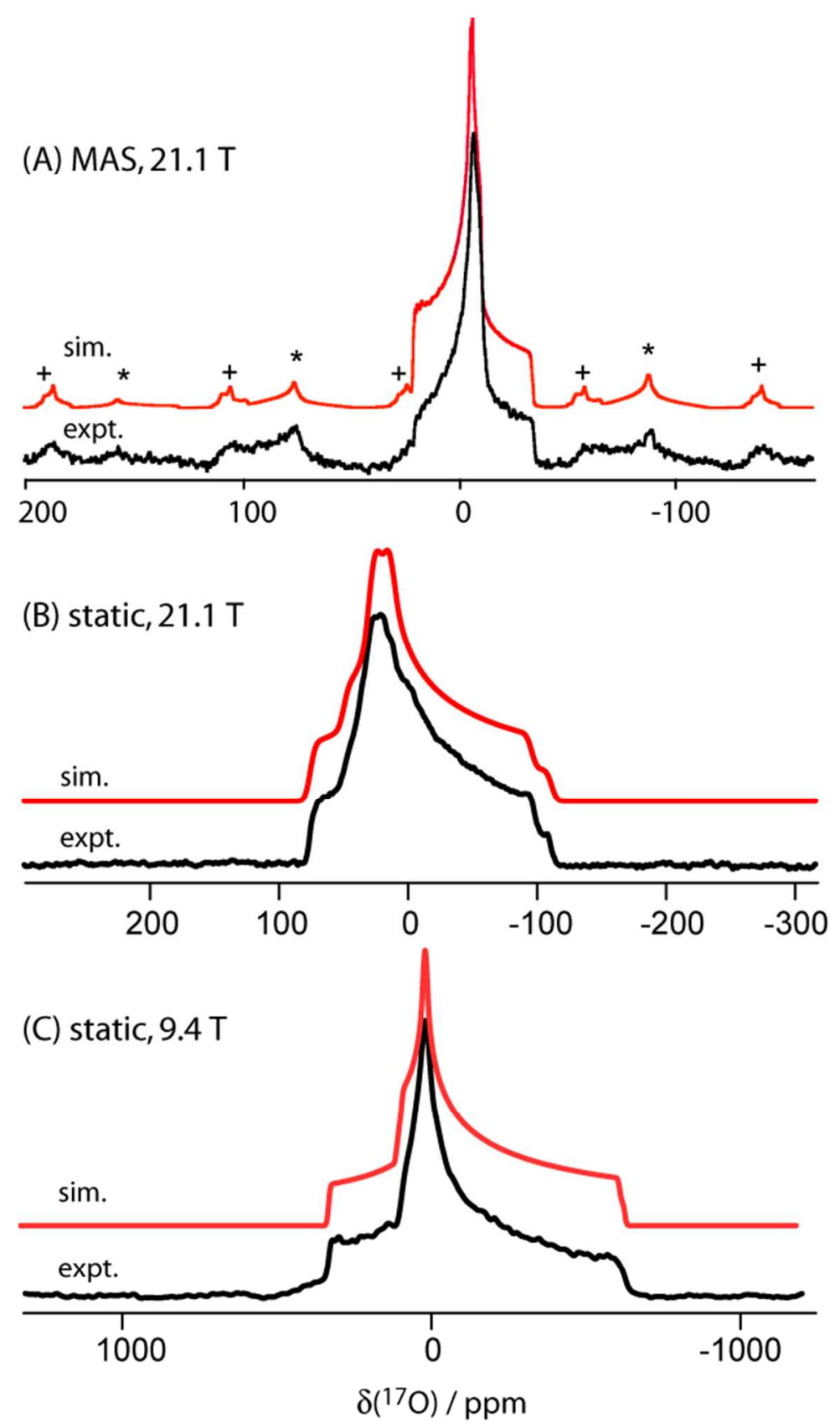

Figure 3. Oxygen-17 NMR spectra of solid powdered barium chlorate monohydrate (2). The signal is due to the ${ }^{17} \mathrm{O}$-isotopically enriched water molecule in the compound. (A) MAS at $21.1 \mathrm{~T}$; (B) stationary sample at $21.1 \mathrm{~T}$; (C) stationary sample at $9.4 \mathrm{~T}$. The asterisks in (A) denote spinning sidebands associated with the central transition. The + symbols in $(\mathrm{A})$ denote the centreband and spinning sidebands due to the satellite transitions. 

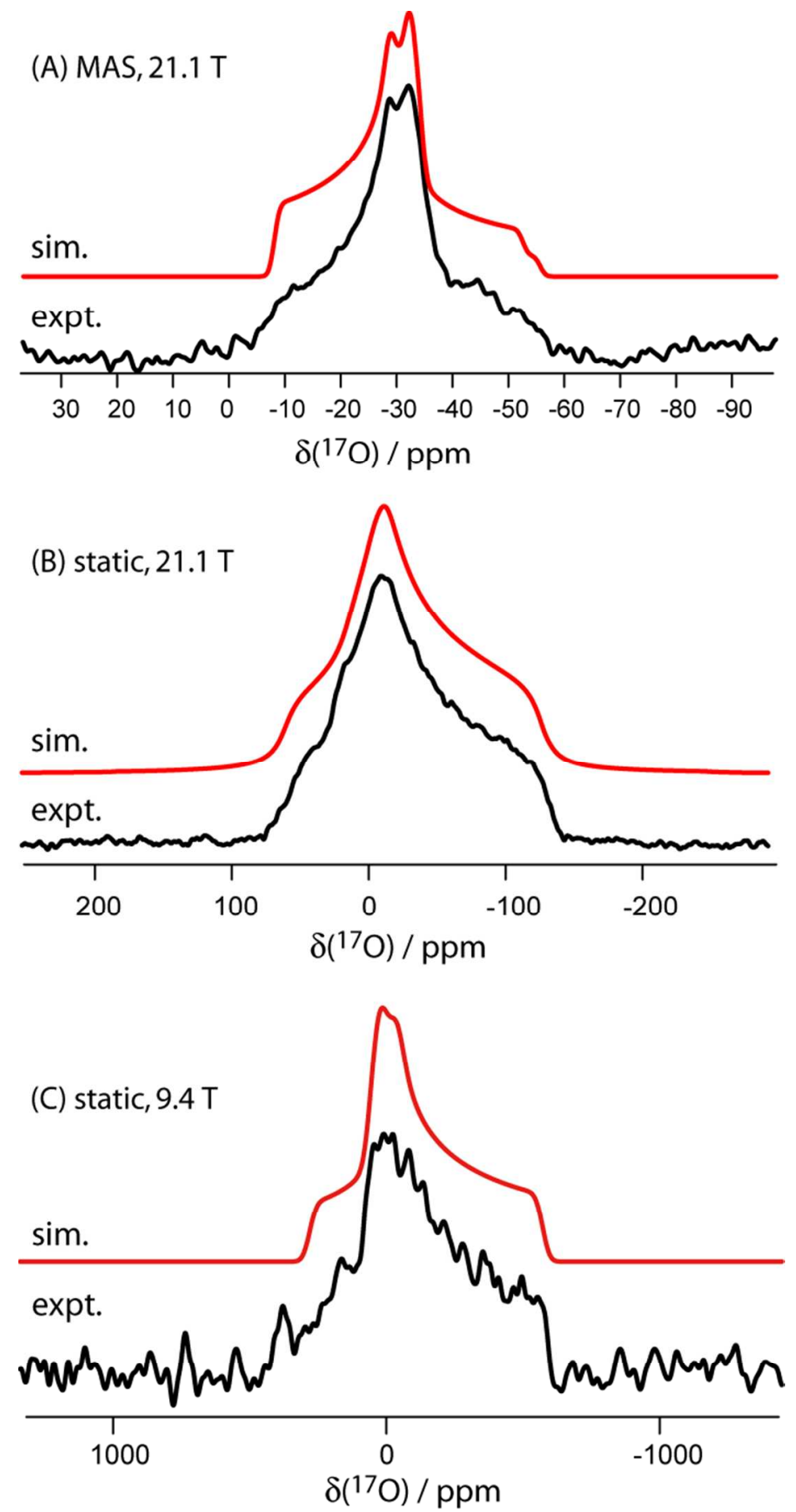

Figure 4. Oxygen-17 NMR spectra of solid powdered lithium sulfate monohydrate (3). The signal is due to the ${ }^{17} \mathrm{O}$-isotopically enriched water molecule in the compound. (A) MAS at 21.1 $\mathrm{T}$; (B) stationary sample at $21.1 \mathrm{~T}$; (C) stationary sample at 9.4 T. 

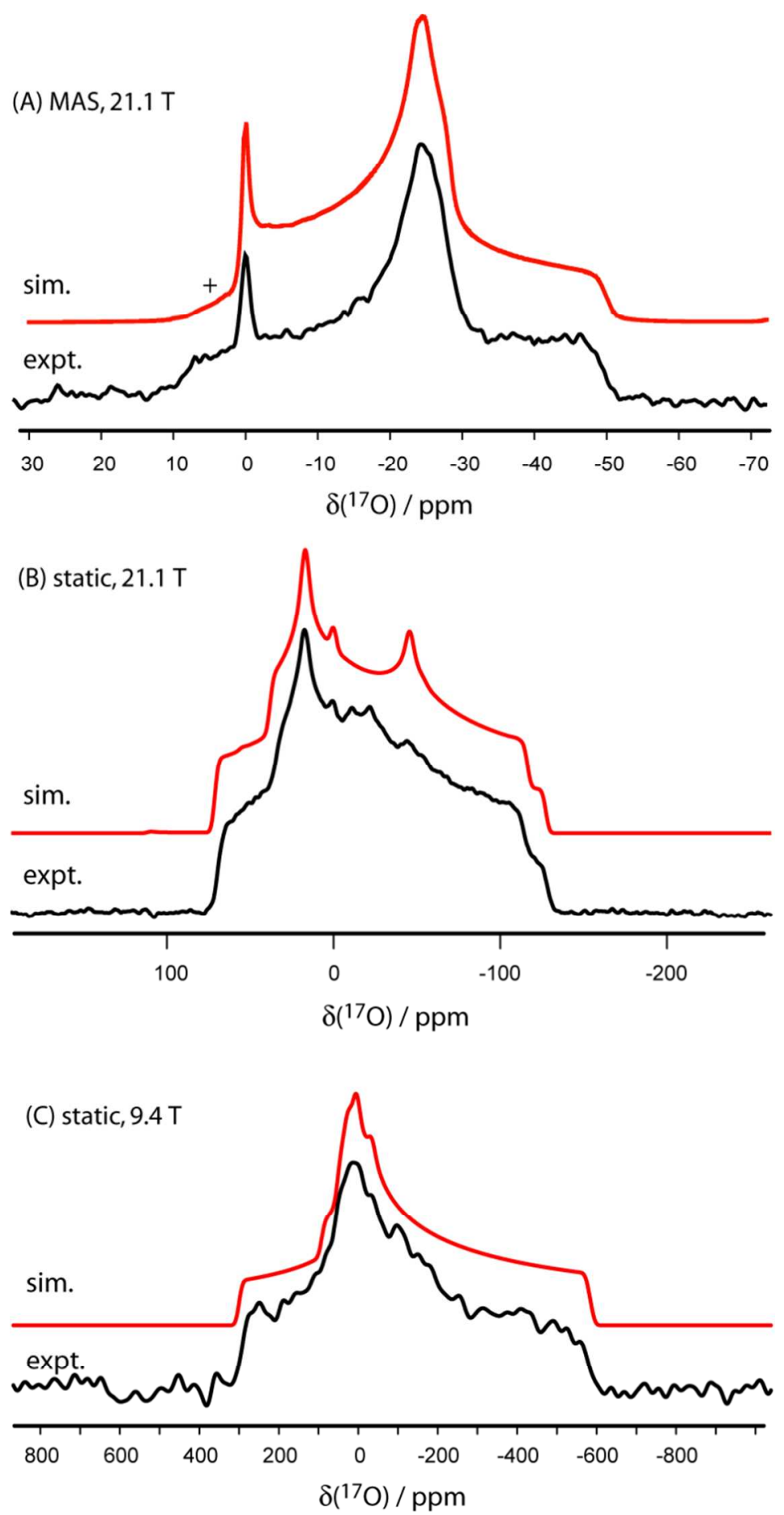

Figure 5. Oxygen-17 NMR spectra of solid powdered potassium oxalate monohydrate (4). The signal is due to the ${ }^{17} \mathrm{O}$-isotopically enriched water molecule in the compound. (A) MAS at 21.1 T; (B) stationary sample at $21.1 \mathrm{~T}$; (C) stationary sample at $9.4 \mathrm{~T}$. The + symbol in (A) denotes signal due to the satellite transition. The sharp spike at $0 \mathrm{ppm}$ in (A) is due to liquid water. 

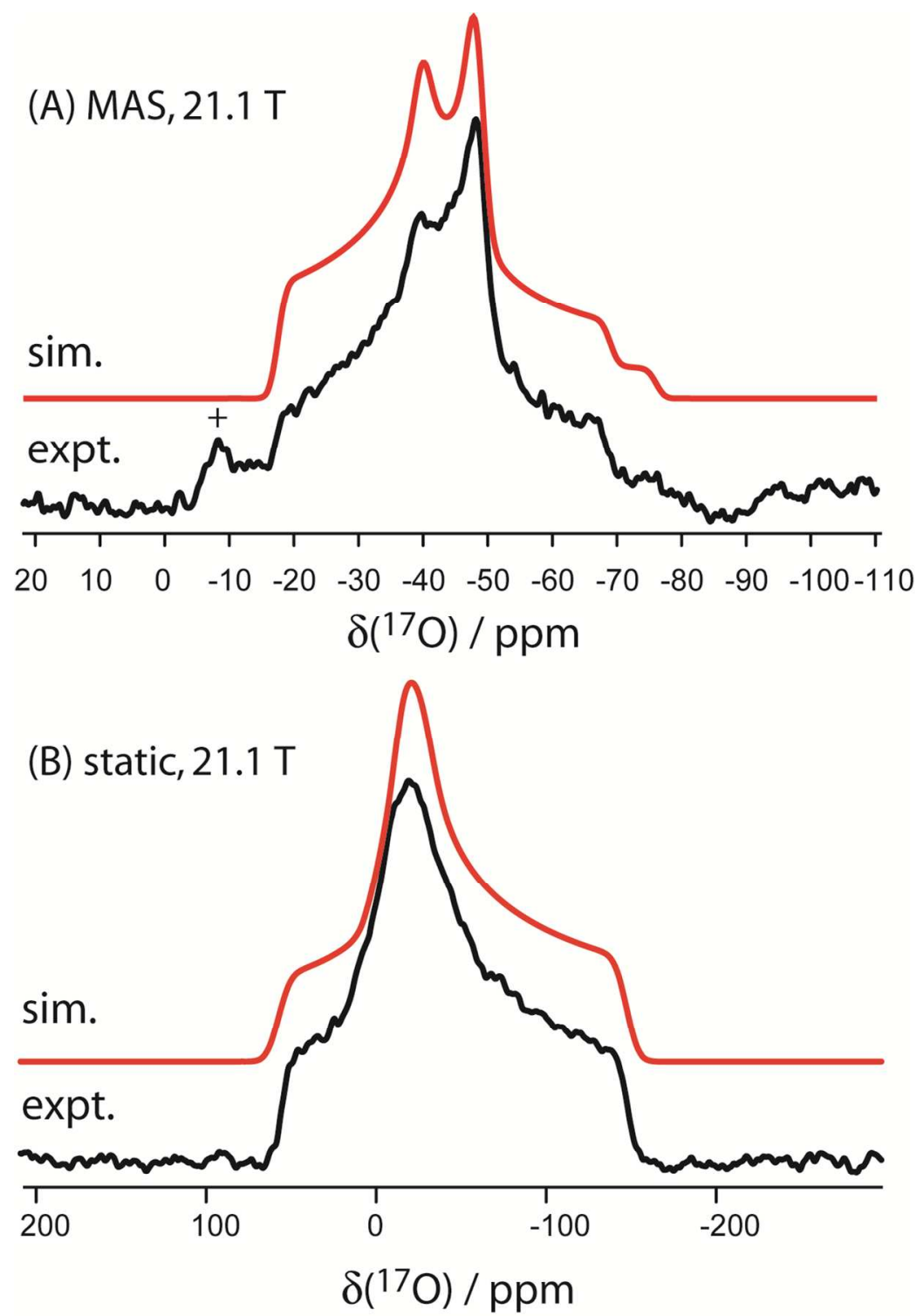

Figure 6. Oxygen-17 NMR spectra of solid powdered sodium perchlorate monohydrate (5). The signal is due to the ${ }^{17} \mathrm{O}$-isotopically enriched water molecule in the compound. (A) MAS at $21.1 \mathrm{~T}$; (B) stationary sample at $21.1 \mathrm{~T}$. The + symbol in (A) denotes signal due to the satellite transition. 


\section{References}

${ }^{1}$ Franks, F. Water: A Matrix of Life, Second edition, The Royal Society of Chemistry: Cambridge, 2000.

${ }^{2}$ Lécuyer, C. Water on Earth: Physicochemical and Biological Properties, Wiley: London, 2014.

${ }^{3}$ Yamazaki, T.; Fenniri, H.; Kovalenko, A. ChemPhysChem 2010, 11, 361.

${ }^{4}$ Xu, W.; Hausner, D. B.; Harrington, R.; Lee, P. L.; Strongin, D. R.; Parise, J. B. Am. Mineral. 2011, 96, 513.

${ }^{5}$ Bobylev, I. B.; Gerasimov, E. G.; Zyuzeva, N. A. Phys. Sol. State 2014, 56, 1742.

${ }^{6}$ Yoder, C. H.; Pasteris, J. D.; Worcester, K. N.; Schermerhorn, D. V. Calcif. Tissue Int. 2012, 90,60 .

${ }^{7}$ Lebofsky, L. A.; Feierberg, M. A.; Tokunaga, A. T.; Larson, H. P.; Johnson, J. R. Icarus 1981, 48, 453.

${ }^{8}$ Westhof, E., Ed. Water and Biological Macromolecules, CRC Press: Boca Raton, 1993.

${ }^{9}$ Bell, D. R.; Rossman, G. R. Science 1992, 255, 1391.

${ }^{10}$ Vogt, F. G.; Brum, J.; Katrincic, L. M.; Flach, A.; Socha, J. M.; Goodman, R. M.; Haltiwanger, R. C. Cryst. Growth Des. 2006, 6, 2333.

${ }^{11}$ Airaksinen, S.; Karjalainen, M.; Shevchenko, A.; Westermarck, S.; Leppänen, E.; Rantanen, J.; Yliruusi, J. J. Pharm. Sci. 2005, 94, 2147.

${ }^{12}$ Smith, G.; Wermuth, U. D.; White, J. D. Acta Cryst. C 2007, 63, o489.

13 Tominaga, M.; Masu, H.; Azumaya, I. CrystEngComm 2011, 13, 5299.

${ }^{14}$ Wagner, G.; Pardi, A.; Wüthrich, K. J. Am. Chem. Soc. 1983, 105, 5948.

15 Aliev, A. B.; Harris, K. D. M. Struct. Bonding 2004, 108, 1.

${ }^{16}$ Wu, G.; Freure, C. J.; Verdurand, E. J. Am. Chem. Soc. 1998, 120, 13187.

${ }^{17}$ Wu, G. Prog. Nucl. Magn. Reson. Spectrosc. 2008, 52, 118.

${ }^{18}$ Spiess, H. W.; Garrett, B. B.; Sheline, R. K.; Rabideau, S. W. J. Chem. Phys. 1969, 51, 1201.

${ }^{19}$ Waldstein, P.; Rabideau, S. W. J. Chem. Phys. 1967, 47, 5338.

${ }^{20}$ Edmonds, D. T.; Zussman, A. Phys. Lett. 1972, 41A, 167.

${ }^{21}$ Ludwig, R.; Weinhold, F.; Farrar, T. C. J. Chem. Phys. 1995, 103, 6941. 
${ }^{22}$ Puzzarini, C.; Cazzoli, G.; Harding, M. E.; Vázquez, J.; Gauss, J. J. Chem. Phys. 2015, 142, 124308.

${ }^{23}$ Ba, Y.; Ripmeester, J. A.; Ratcliffe, C. I. Can. J. Chem. 2011, 89, 1055-1064.

${ }^{24}$ Michaelis, V. K.; Keeler, E. G.; Ong, T.-C.; Craigen, K. N.; Penzel, S.; Wren, J. E. C.; Kroeker, S.; Griffin, R. G. J. Phys. Chem. B 2015, 119, 8024.

${ }^{25}$ Fedotov, M. NMR in Inorganic and Coordination Chemistry, Cambridge International Science Publishing Ltd., 2016.

${ }^{26}$ Fedotov, M. A.; Belyaev, A. V. Russ. J. Inorg. Chem. 2008, 53, 761-764.

${ }^{27}$ Fedotov, M. A. Russ. Chem. Bull., Int. Ed. 2003, 52, 781-794.

${ }^{28}$ Fedotov, M. A. Russ. J. Coord. Chem. 2002, 28, 573-580.

${ }^{29}$ Belyaev, A. V.; Fedotov, M. A.; Shagabutdinova, S. N. Russ. J. Coord. Chem. 2007, 33, 136139.

${ }^{30}$ Castillo-Blum, S. E.; Richens, D. T.; Sykes, A. G. Inorg. Chem. 1989, 28, 954-960.

${ }^{31}$ Wu, G.; Rovnyak, D.; Huang, P. C.; Griffin, R. G. Chem. Phys. Lett. 1997, 277, 79-83.

${ }^{32}$ Rovnyak, D.; Filip, C.; Itin, B.; Stern, A. S.; Wagner, G.; Griffin, R. G.; Hoch, J. C. J. Magn. Reson. 2003, 161, 43-55.

${ }^{33}$ Bodart, P. R.; Amoureux, J.-P.; Dumazy, Y.; Lefort, R. Mol. Phys. 2000, 98, 1545-1551.

${ }^{34}$ Eichele, K. WSolids NMR Simulation Package, version 1.20.22, 1994 and 2014.

${ }^{35}$ TopSpin version 3.0 (Bruker), 2010.

${ }^{36}$ Clark, S. J.; Segall, M. D.; Pickard, C. J.; Hasnip, P. J.; Probert, M. J.; Refson, K.; Payne, M. C. Z. Kristallogr. 2005, 220, 567-570.

37 (a) Perdew, J. P.; Burke, K.; Ernzerhof, M. Phys. Rev. Lett. 1996, 77, 3865-3868 (b) Perdew, J. P.; Burke, K.; Ernzerhof, M. Phys. Rev. Lett. 1997, 78, 1396.

${ }^{38}$ Sabine, T. M.; Cox, G. W.; Craven, B. M. Acta Cryst. 1969, B25, 2437-2441.

${ }^{39}$ Coppens, P.; Sabine, T. M. Acta Cryst. 1969, B25, 2442-2451.

${ }^{40}$ Sikka, S. K.; Momin, S. N.; Rajagopal, H.; Chidambaram, R. J. Chem. Phys. 1968, 48, 18831890.

${ }^{41}$ Lundgren, J.-O.; Kvick, Å.; Karppinen, M.; Liminga, R.; Abrahams, S. C. J. Chem. Phys. 1984, 80, 423.

${ }^{42}$ Sequeira, A.; Srikanta, S.; Chidambaram, R. Acta Cryst. 1970, B26, 77-80. 
${ }^{43}$ Berglund, B.; Tellgren, R.; Thomas, J. O. Acta Cryst. 1976, 32, 2444-2449.

${ }^{44}$ Zhang, Q. W.; Zhang, H. M.; Usha, M. G.; Wittebort, R. J. Solid State Nucl. Magn. Reson. 1996, $7,147$.

${ }^{45}$ Zhang, Q.; Chekmenev, E. Y.; Wittebort, R. J. J. Am. Chem. Soc. 2003, 125, 9140-9146.

${ }^{46}$ Shporer, M.; Achlama, A. M. J. Chem. Phys. 1976, 65, 3657.

${ }^{47}$ Wu, G.; Hook, A.; Dong, S.; Yamada, K. J. Phys. Chem. A 2000, 104, 4102.

${ }^{48}$ Leskes, M.; Moore, A. J.; Goward, G. R.; Grey, C. P. J. Phys. Chem. C 2013, 117, 26929.

${ }^{49}$ Brandenburg, K. Diamond Version 4.1.0, Crystal Impact GbR, Bonn, Germany, 1997-2015. 